\title{
Impact of clinical factors and allograft leukocyte content on post-transplant lymphopenia, monocytopenia, and survival in patients undergoing allogeneic peripheral blood haematopoietic cell transplant
}

Mary D Thoma', Jennifer Glejf², Eapen Jacob², Tanya J Huneke, Lori J DeCook³, Nicci D Johnson',

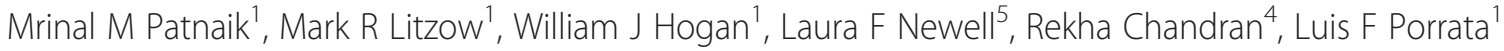
and Shernan G Holtan ${ }^{1,5,6^{*}}$

\begin{abstract}
Background: We have previously shown that lymphopenia and monocytopenia at 2-3 months post-allogeneic haematopoietic cell transplant (HCT) is associated with poor survival in recipients of both myeloablative and reduced intensity conditioning regimens. It is not known whether the graft leukocyte content has a role in early lymphocyte and monocyte recovery following allogeneic T-cell replete peripheral blood HCT.
\end{abstract}

Methods: Haematologic recovery data, including absolute lymphocyte and monocyte counts (ALC and AMC, respectively) at day $+15,+30,+60$, and +100 , and outcomes data were pooled from two prior independent cohorts, and parameters were correlated with leukocyte graft content in those individuals receiving peripheral blood progenitor cell grafts. 216 consecutive patients from 2001-2010 were included in the analysis.

Results: Neither infused allograft lymphocyte, monocyte, granulocyte, nor CD34+ cell number per kilogram recipient body weight correlated with haematologic recovery parameters or overall survival in this cohort. Prognostic factors for overall survival based on multivariate analysis were as expected from the results of the previous independent cohorts and included severity of chronic GVHD ( $p<0.001)$, development of post-transplant relapse $(p=0.001)$, day $+60 \mathrm{AMC}>0.3 \times 10^{9}$ cells $/ L(p=0.0015)$, and day $+100 \mathrm{ALC}>0.3 \times 10^{9}$ cells $/ \mathrm{L}(p<0.001)$. Low monocyte and lymphocyte counts at the day +60 and day +100 time points were significantly associated with acute GVHD and/or CMV viraemia.

Conclusions: This study suggests that graft cell count does not influence post-transplant monocyte and lymphocyte recovery following T-cell replete allogeneic peripheral blood HCT. Post-transplant complications such as acute GVHD and/or CMV viraemia negatively influenced monocyte and lymphocyte recovery, and hence the survival. Further studies aimed at understanding the mechanisms behind sustained lymphopenia and monocytopenia post-transplant are needed.

Keywords: Allogeneic haematopoietic cell transplantation, Lymphopenia, Monocytopenia, GVHD, CMV viraemia

\footnotetext{
*Correspondence: sgholtan@umn.edu

'Department of Medicine, Division of Hematology, Mayo Clinic Graduate

School of Medicine, Rochester, MN, USA

${ }^{5}$ Center for Hematologic Malignancies, Knight Cancer Institute, Oregon

Health \& Science University, Portland, OR, USA

Full list of author information is available at the end of the article
} 


\section{Background}

The development of cytopenias after initial donor haematopoietic cell engraftment is a risk factor for poor transplant outcomes [1]. We have previously identified that significant lymphopenia and monocytopenia, defined as an absolute lymphocyte or monocyte count (ALC and AMC, respectively) of $<0.3 \times 10^{9}$ cells/L at day +100 post-transplant, are independent risk factors for inferior survival $[2,3]$. The objective of this study was to determine whether the leukocyte content of the T-cell replete peripheral blood haematopoietic cell allograft is responsible at least in part for post-transplant ALC and AMC recovery in the first 100 days post-HCT, or whether the secondary cytopenias predominantly reflect the detrimental impact of transplant complications on graft function and immune reconstitution. Allograft monocytes have previously been shown to suppress T-cell proliferation in a dose-dependent fashion, with an associated decrease in acute GVHD risk in retrospective series [4,5]. A previous prospective study of allograft leukocyte content did not identify an association between pot-transplant survival and lymphoid and myeloid reconstitution [6], although monocytes were not analyzed in that study. Clarification of the role of infused graft monocytes in controlling acute graft versus host disease (GVHD) could lead to modification of apheresis strategies or other opportunities for allograft engineering to reduce transplant complications.

\section{Methods}

\section{Patient characteristics}

Patients included in this analysis were pooled from our prior two reports, a myeloablative (MA) cohort of 135 patients, and a reduced intensity (RIC) cohort of 118 patients $[2,3]$. Patients receiving bone marrow grafts were eliminated from the analysis (24 from the MA and 8 from the RIC cohorts). Of the 221 remaining patients, 5 did not have complete data on graft leukocyte subsets, leaving 216 consecutive patients available for analysis in this study. All patients underwent allogeneic HCT from 2001-2010 at Mayo Clinic in Rochester, MN. All patients gave written consent to use their medical records for research. No patients were lost to follow-up. Approval for the retrospective review of these records was obtained from the Mayo Clinic Institutional Review Board and was in accordance with US federal regulations and the Declaration of Helsinki.

\section{Determination of allograft leukocyte subset content}

Lymphocyte, granulocyte, and monocyte content was obtained prior to $11 / 13 / 2009$ by manual differentials using standard clinical criteria. After that time, flow cytomtery using a BD FACSCalibur (Becton Dickinson Biosciences, San Jose, California) was used to determine product content using forward and side scatter characteristics of the lymphocyte, granulocyte and monocytes. This method was validated in the laboratory and proven to be consistent with prior results with manual differentials. CD34 positive cell content was determined by flow cytometry using the Stem-Kit (Beckman Coulter, Brea, California) in combination with BD TruCount beads in a lab developed test. All data were obtained from results generated during routine clinical care.

\section{End points}

The primary end point of the study was to determine the association of allograft leukocyte content on overall survival, post-transplant complications, and peripheral blood ALC and AMC at day $+15,+30,+60$, and +100 postHCT. Enumeration of leukocyte subsets, including CD34+ cells, granulocytes, monocytes, and lymphocytes was performed on fresh allografts after apheresis and prior to transplant per institutional standard operating procedures. The ALC and AMC were obtained by review of the medical records of the complete blood cell count $(\mathrm{CBC})$ [7] at day $+15,+30,+60$, and +100 post-HCT.

\section{Prognostic factors and survival}

The prognostic factors evaluated in the study included: graft leukocyte subset content, age at transplant, disease status at transplant, related versus unrelated donor stem cell source, degree of HLA-matching, treatment of confirmed, quantifiable CMV viraemia by PCR with ganciclovir or valganciclovir prior to day +100 , presence/ grade of acute GVHD based upon the Glucksberg-Seattle grading system [8], presence/severity of chronic GVHD based upon NIH consensus criteria [9] and ALC and AMC recovery post-HCT. Overall survival (OS) was defined from the time of transplant to last follow-up or death due to any cause.

\section{Statistical analysis}

OS estimates were determined using the approach of Kaplan and Meier [10]. Differences between survival curves were tested for statistical significance using the 2-tailed log-rank test. The Cox proportional hazard model was used for univariate analysis of continuous variable as well as multivariate analysis. Graft leukocyte subsets were analyzed as continuous variables. Dividing the graft subsets in half, in tertiles, or in quartiles, did not change the results of the analysis (not shown). Associations between categorical variables were determined by Fisher's exact test. Correlations between continuous variables were determined by Spearman's rho. Because of multiple comparisons with the correlation analysis, a Bonferroni correction was applied. All p-values represented were two-sided and statistical significance was declared at $\mathrm{p}<0.05$. 
Table 1 Patient characteristics and univariate survival analysis

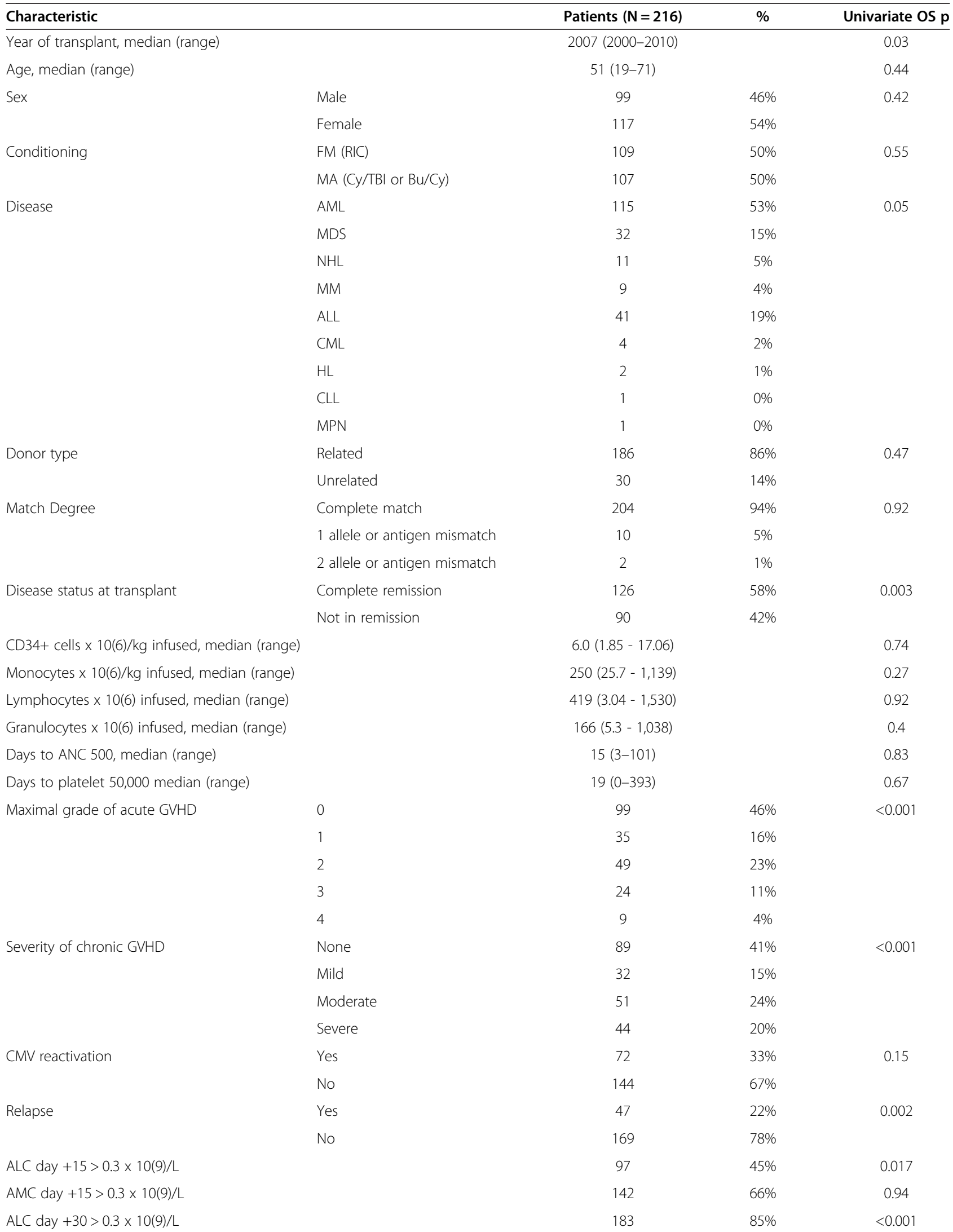


Table 1 Patient characteristics and univariate survival analysis (Continued)

\begin{tabular}{llll}
\hline AMC day $+30>0.3 \times 10(9) / L$ & 193 & $89 \%$ & 0.001 \\
ALC day $+60>0.3 \times 10(9) / L$ & 172 & $80 \%$ & 0.0004 \\
AMC day $+60>0.3 \times 10(9) / L$ & 138 & $64 \%$ & $<0.001$ \\
ALC day $+100>0.3 \times 10(9) / L$ & 158 & $73 \%$ & $<0.001$ \\
AMC day $+100>0.3 \times 10(9) / L$ & 139 & $64 \%$ & $<0.001$ \\
\hline
\end{tabular}

\section{Results and discussion}

\section{Patient characteristics}

Patient characteristics are described in Table 1 . The median age of the cohort was 51 years with a slight female predominance (54\%). The underlying disease was AML in $53 \%$. All patients received consistent supportive care including calcineurin inhibitor-based graft-versus-host disease prophylaxis. The majority of the stem cell grafts were derived from fully-matched related donors (86\%). Over half of patients underwent allogeneic HCT in first remission (58\%). Median overall survival for the entire cohort was 26.6 months. 109 patients died at the time of analysis, and the median follow up for surviving patients was 50.1 months. 68 patients $(31 \%)$ in this cohort died from non-relapse complications, and 41 patients (19\%) died from relapse.

\section{Allograft leukocyte content, ALC and AMC recovery, and survival: Univariate analysis}

No graft leukocyte subset was associated with OS as a continuous variable (Table 1), or divided above/below the median, or in quartiles (not shown). As expected from our prior reports, ALC and AMC $>0.3 \times 10^{9} / \mathrm{L}$ was

Table 2 Association of graft leukocytes with clinical outcomes

\begin{tabular}{llc}
\hline Category & Cells/kg & $\mathbf{p}$ \\
\hline Acute GVHD & Graft monocytes & 0.35 \\
& Graft lymphocytes & 0.08 \\
& Graft granulocytes & 0.56 \\
Graft CD34+ & 0.62 \\
Chronic GVHD & Graft monocytes & 0.18 \\
& Graft lymphocytes & 0.65 \\
CMV reactivation & Graft granulocytes & 0.4 \\
& Graft CD34+ & 0.24 \\
& Graft monocytes & 0.1 \\
Relapse & Graft lymphocytes & 0.14 \\
& Graft granulocytes & 0.32 \\
& Graft CD34+ & 0.07 \\
& Graft monocytes & 0.23 \\
& Graft lymphocytes & 0.51 \\
& Graft granulocytes & 0.28 \\
& Graft CD34+ & 0.1 \\
\hline
\end{tabular}

associated with improved survival, especially at the day +30 , 60, and day +100 time points. Graft leukocyte subsets were not associated with the development of the clinical outcomes of acute GVHD, chronic GVHD, CMV reactivation, or relapse (Table 2). Graft leukocyte subsets did not correlate with post-transplant ALC or AMC at any of the time points measured (Table 3 ).

\section{Multivariate analysis}

Multivariate analysis (Table 4) including the parameters that demonstrated a significant difference in overall survival in the univariate analysis revealed the following independent prognostic factors: severity of chronic GVHD, development of post-HCT relapse, day +60 AMC, and day +100 ALC. Day +60 monocytopenia occurred in 57 patients and was associated with day +100 lymphopenia $(\mathrm{p}=0.05)$, which occurred in 18 patients.

\section{Association of monocytopenia, lymphopenia, and GVHD}

Acute GVHD was associated with day +60 monocytopenia (median 0.2 vs. $0.3 \times 10^{9} / \mathrm{L}, \mathrm{p}=0.01$ ) and less so with day +100 lymphopenia (median 0.5 vs. $0.6 \times 10^{9} / \mathrm{L}$, $\mathrm{p}=0.05)$.

Table 3 Associated variables

\begin{tabular}{llcc}
\hline Variable & By variable & Spearman's rho & $\mathbf{p}$ \\
\hline D15AMC & D15ALC & 0.65 & $<.0001$ \\
Graft Mono/kg & Graft Lymph/kg & 0.61 & $<.0001$ \\
Graft Gran/kg & Graft Mono/kg & 0.53 & $<.0001$ \\
D100ALC & D60ALC & 0.56 & $<.0001$ \\
D30AMC & D30ALC & 0.50 & $<.0001$ \\
Graft Gran/kg & Graft Lymph/kg & 0.48 & $<.0001$ \\
D100AMC & D100ALC & 0.50 & $<.0001$ \\
D30ALC & D15ALC & 0.40 & $<.0001$ \\
D60ALC & D30ALC & 0.38 & $<.0001$ \\
D100AMC & D60AMC & 0.38 & $<.0001$ \\
D60AMC & D60ALC & 0.36 & $<.0001$ \\
D100ALC & D30ALC & 0.30 & 0.014 \\
D60ALC & D15ALC & 0.28 & 0.02 \\
D30AMC & D15ALC & 0.27 & 0.02 \\
D100ALC & D15ALC & 0.28 & 0.03 \\
D100AMC & D15AMC & 0.28 & 0.05 \\
\hline
\end{tabular}

Only statistically significant relationships are shown 
Table 4 Multivariate analysis

\begin{tabular}{lccc}
\hline & RR & $\mathbf{9 5 \% ~ C l}$ & $\mathbf{P}$ \\
\hline cGVHD severity & & & $<0.001$ \\
mild vs. none & 0.3 & $0.12-0.64$ & \\
mild vs. moderate & 0.88 & $0.32-2.3$ & \\
mild vs. severe & 0.26 & $0.1-0.68$ & \\
Relapse & 2.7 & $1.64-4.35$ & 0.0001 \\
D60 AMC $>0.3 \times 10(9) / L$ & 0.44 & $0.26-0.73$ & 0.0015 \\
D100 ALC $>0.3 \times 10(9) / L$ & 0.22 & $0.11-0.46$ & $<0.001$ \\
\hline
\end{tabular}

\section{Association of monocytopenia, lymphopenia, and CMV}

CMV reactivation was strongly associated with day +60 monocytopenia but no other longitudinal haematopoietic parameter in this study (median 0.1 vs. $0.4 \times 10^{9} / \mathrm{L}$ for those who did vs. did not receive treatment for CMV reactivation prior to day $+100, \mathrm{p}<0.001)$.

Association of monocytopenia, lymphopenia, and relapse Day +100 ALC was lower in patients who experienced subsequent relapse of their underlying malignancy $\left(0.3\right.$ vs. $\left.0.6 \times 10^{9} / \mathrm{L}, \mathrm{p}=0.03\right)$. No other associations between cytopenias and transplant complications were identified at the other time points studied.

Association of monocytopenia, lymphopenia, overlapping transplant complications, and long term survival

Recognizing that patients can have multiple complications at once, we constructed a Venn diagram that depicts overlapping of post-transplant complications (acute GVHD, CMV reactivation, and relapse) in patients with the most prevalent prognostic laboratory value in this series, day +60 monocytopenia (Figure 1). Over $90 \%$ of the 57 patients with day +60 monocytopenia had concurrent acute GVHD and/ or CMV reactivation (Figure 1). Importantly, day +60

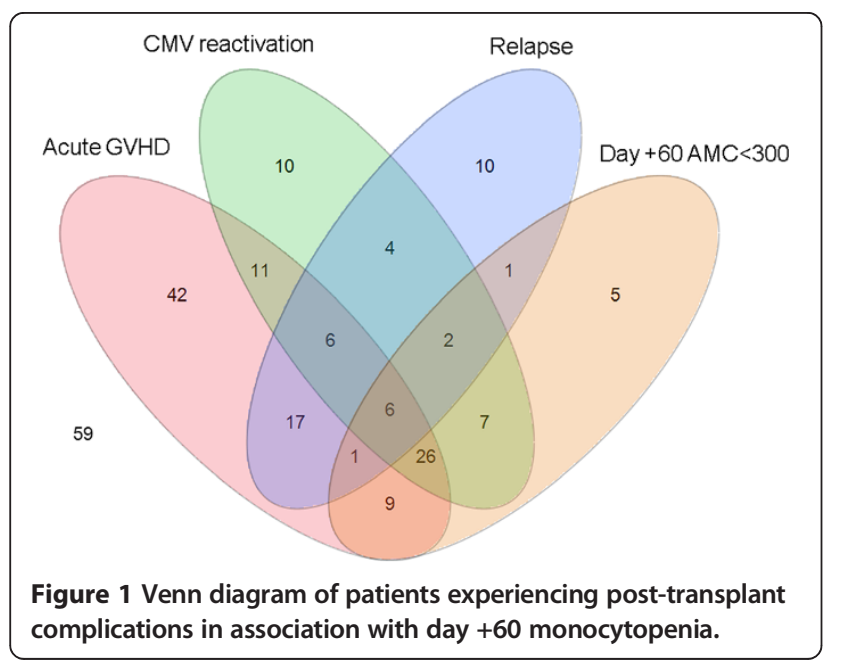

monocytopenia in the setting of acute GVHD and CMV reactivation negatively impacted survival (Figure 2). In an effort to understand additional risk factors for these secondary cytopenias, increasing age showed a trend toward failure to achieve the $0.3 \times 10^{9} / \mathrm{L}$ AMC threshold at day $+60(p=0.07)$, but no other host or graft factors could be identified at this or other time points for ALC or AMC. All 2 year survivors (81 patients, 38\%) met the predetermined either day +60 AMC or day +100 ALC threshold of $>0.3 \times 10^{9} / \mathrm{L}$, and majority of them met both (Figure 3). Of the 55 patients who met both ALC and AMC thresholds but did not survive 2 years, 41 of them (75\%) died from relapsed disease. 39 patients who did not meet the ALC or AMC thresholds did not survive 2 years.

\section{Is there an optimal cellular composition of allografts?}

In this report, we demonstrate that post-allogeneic HCT lymphopenia and monocytopenia in the intermediate recovery phase post-HCT are related to early complications rather than allograft leukocyte content. This is in contrast to the autologous transplantation setting, where the autograft lymphocyte and monocyte content directly correlates with post-transplant lymphocyte and monocyte recovery and survival [11-14]. In our cohort, we identified age as a possible contributor to post-transplant secondary cytopenias, as have others [1]. Similarly, a recent analysis of lymphocyte populations in patients enrolled in Blood and Marrow Transplant Clinical Trials Network trial 0302 also identified that patients responding to therapy for acute GVHD, regardless of the treatment arm, had a less substantial decline in peripheral blood CD45+ leukocytes compared to those who were not responding to treatment [15]. However, other studies have identified a correlation with various components of allografts and post-HCT hematopoiesis and outcomes [6,16-19]. It is possible that more refined subsets other than simple granulocyte, monocyte, and lymphocyte content of the graft relates to outcomes. Lonial et al recently identified that granulocytemacrophage colony stimulating factor given concomitantly with G-CSF mobilized fewer plasmacytoid dendritic cells and T cells from HLA-matched sibling donors, leading to more rapid immunologic recovery but with no overall impact on survival [20].

\section{What are the mechanisms behind post-HCT cytopenias?}

Medications, especially steroids and ganciclovir, are well known to cause cytopenias, predominantly lymphopenia with the former and neutropenia with the latter, although such side effects are not universal among HCT recipients. Efforts to better understand other mechanisms of posttransplant cytopenias are ongoing, including the potential role of pro-inflammatory cytokines such as tumor-necrosis factor-alpha (TNF- $\alpha$ ) and interferon-gamma (IFN- $\gamma$ ) on the suppression of hematopoiesis occurring after HCT. As 


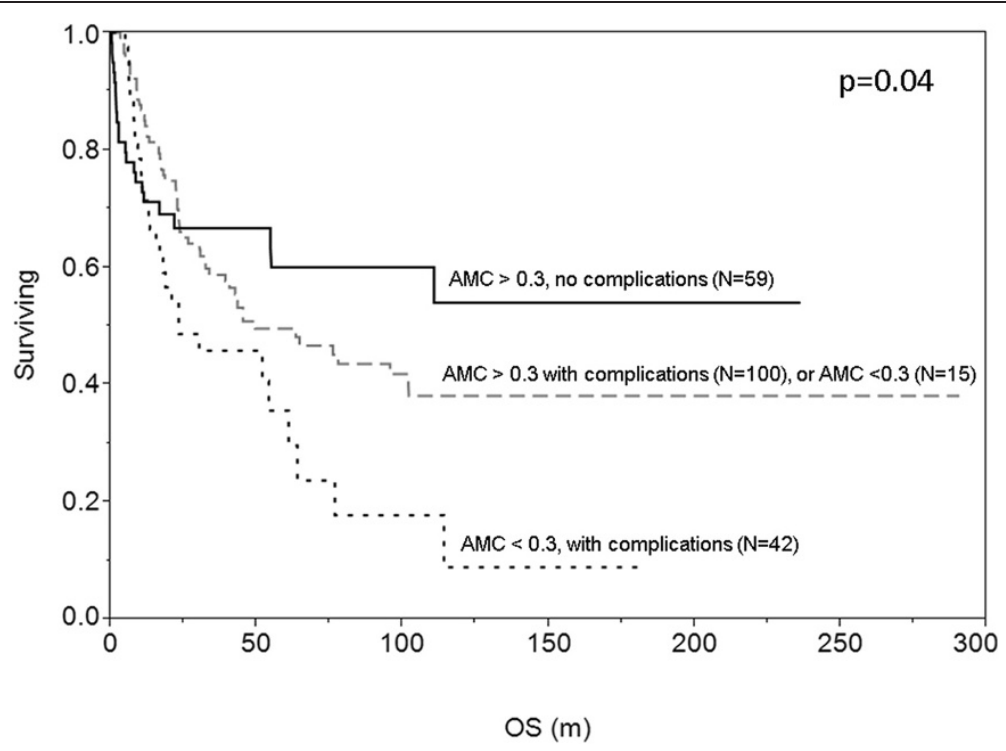

Figure 2 Kaplan Meier estimate of patients experiencing post-transplant complications in association with day +60 monocytopenia.

previously described, chemotherapy and radiation conditioning regimens administered prior to HCT lead to damage of host tissues, production of pro-inflammatory cytokines [i.e. TNF- $\alpha$, interleukin 1 and 6 (IL-1, IL-6)] and other inflammatory stimuli (i.e. lipopolysaccharide, LPS), which then promotes the activation of antigen-presenting cells (APCs) involved in the pathogenesis of acute GHVD [21]. Pro-inflammatory cytokines, and specifically TNF- $\alpha$ and IFN- $\gamma$, have also been implicated in the pathogenesis of

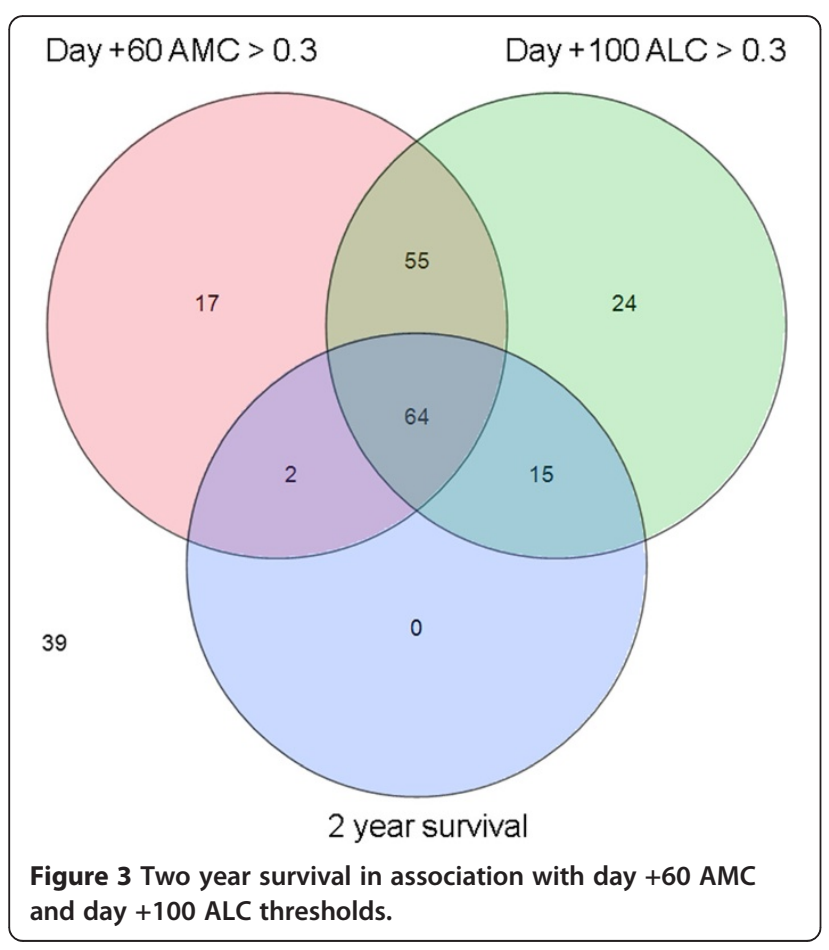

primary bone marrow failure states and haematopoietic stem cell suppression [22-26] and the inflammatory state that develops in the setting of post-HCT complications such as GVHD or infections. Why some patients are more susceptible to secondary cytopenias and marrow suppression, as well as other post-HCT complications, is unclear but may relate to patient-specific and disease-specific differences such as specific single-nucleotide polymorphisms as well as non-HLA genetic variation within the major histocompatibility complex [27-31] or other mechanisms. The role of these patient and disease variables, as well as the contribution of cytokine fluctuations [32], on post-HCT cytopenias, immunologic reconstitution, as well as post-HCT outcomes, is an area of active investigation and remains to be fully elucidated.

\section{Limitations}

Our study has several limitations. This retrospective cohort was transplanted at a single institution, where the majority of transplants were from HLA-matched sibling donors. These results may not be applicable to the minimal intensity setting, nor to cohorts where the majority of grafts are derived from unrelated or alternate donors, although early lymphocyte recovery has previously shown to be prognostic after T-cell depleted grafts, [33] umbilical cord blood grafts [34], and unmanipulated haploidentical grafts [35]. In the latter study, a lymphocyte recovery threshold of $>0.3 \times 10^{9} / \mathrm{L}$ at day +30 was also shown to significantly impact OS, PFS, relapse and TRM and was significantly correlated with CD3+ T cells in the allograft [35]. Additionally, detailed flow cytometric phenotyping of cellular subsets was also not performed (e.g., graft regulatory $\mathrm{T}$ cells [36]), and all data 
was generated from that encountered during routine clinical care. Therefore to confirm the findings of this study, a larger retrospective study using CIBMTR database of over 30,000 HCT procedures is being performed. While confirmatory studies are underway, this study suggests that both monocytopenia and lymphopenia at 2-3 months post-HCT are emerging predictors of poor survival. Development of these secondary cytopenias appears to be related to the development of acute GVHD and CMV viraemia and possibly recipient age, as opposed to graft leukocyte content or other established clinical factors.

Although allogeneic transplantation offers the only curative option for many advanced and high-risk haematologic malignancies, the costs associated with the procedure have come under increased scrutiny (\$96,000 -\$204,000 in the first year in 2012) [37]. The single biggest driver of expenditure is the length of inpatient hospital stay [37]. The role of cytopenias is particularly important given its associations with acute GVHD and infections, both of which frequently necessitate hospital admissions [38]. Patients with secondary cytopenias may be those requiring increased resource utilization. Therefore, this group of patients may be appropriate for early, novel interventions to facilitate haematologic and immune recovery. If our findings are confirmed in larger studies, it would provide a rationale for conducting clinical trials to proactively enhance lymphohaematopoietic recovery following allogeneic HCT.

\section{Conclusions}

In our cohort of 216 recipients of peripheral blood progenitor cell allografts, we did not identify a clear role of graft monocyte or other cellular component as being predictive of GVHD, relapse, or survival. Post-transplant lymphopenia and monocytopenia were predominantly associated with acute GVHD and preemptive therapy for CMV viraemia. In patients experiencing these complications but with adequate lymphocyte and monocyte counts at the day +60 and day +100 time points, long term survival did not appear to be negatively impacted. Further studies aimed at understanding which patients are most vulnerable to developing secondary cytopenias, and how to improve immune recovery in the face of these complications, are needed.

\footnotetext{
Abbreviations

ALC: Absolute lymphocyte count; ALL: Acute lymphoblastic leukemia;

AMC: Absolute monocyte count; AML: Acute myeloid leukemia; ANC: Absolute neutrophil count; CLL: Chronic lymphocytic leukemia; Cl: Confidence interval; CML: Chronic myeloid leukemia; CMV: Cytomegalovirus; GVHD: Graft versus host disease; FM: Fludarabine and melphalan; HCT: Haematopoietic cell transplant; HL: Hodgkin lymphoma; HLA: Human leukocyte antigen; KG: Kilogram; MA: Myeloablative; MM: Multiple myeloma; MDS: Myelodysplastic syndrome; MPN: Myeloproliferative neoplasm; NHL: Non-Hodgkin lymphoma; OS: Overall survival; RR: Relative risk.
}

\section{Competing interests}

The authors declare that they have no competing interests.

\section{Authors' contributions}

MT, JG, EJ, TH, LD, and NJ collected and helped analyze data. MP, ML, WH provided patient data and edited the manuscript. LN and RC contributed to study concept and writing the manuscript. LP and SH conceived of the study, analyzed data, and wrote the manuscript. All authors read and approved the final manuscript.

\section{Acknowledgments}

This project was supported in part by the Office of Research in Women's Health and the National Institute of Child Health and Human Development, Oregon BIRCWH Award Number 2K12HD043488-11 (SGH).

\section{Author details}

${ }^{1}$ Department of Medicine, Division of Hematology, Mayo Clinic Graduate School of Medicine, Rochester, MN, USA. ${ }^{2}$ Department of Pathology and Laboratory Medicine, Mayo Clinic Graduate School of Medicine, Rochester, MN, USA. ${ }^{3}$ Department of Medicine, Division of Hematology, Mayo Clinic Graduate School of Medicine, Phoenix, AZ, USA. ${ }^{4}$ Medical College of Wisconsin, Milwaukee, WI, USA. ${ }^{5}$ Center for Hematologic Malignancies, Knight Cancer Institute, Oregon Health \& Science University, Portland, OR, USA.

${ }^{6}$ Blood and Marrow Transplant Program, University of Minnesota, 420 Delaware Street SE, Minneapolis, MN 55455, USA.

Received: 28 January 2014 Accepted: 27 August 2014

Published: 1 September 2014

\section{References}

1. Nakamae H, Storer B, Sandmaier BM, Maloney DG, Davis C, Corey L, Storb R, Boeckh M: Cytopenias after day 28 in allogeneic hematopoietic cell transplantation: impact of recipient/donor factors, transplant conditions and myelotoxic drugs. Haematologica 2011, 96(12):1838-1845.

2. Thoma MD, Huneke TJ, DeCook LJ, Johnson ND, Wiegand RA, Litzow MR, Hogan WJ, Porrata LF, Holtan SG: Peripheral blood lymphocyte and monocyte recovery and survival in acute leukemia postmyeloablative allogeneic hematopoietic stem cell transplant. Biol Blood Marrow Transplant 2012, 18(4):600-607.

3. DeCook LJ, Thoma M, Huneke T, Johnson ND, Wiegand RA, Patnaik MM, Litzow MR, Hogan WJ, Porrata LF, Holtan SG: Impact of lymphocyte and monocyte recovery on the outcomes of allogeneic hematopoietic SCT with fludarabine and melphalan conditioning. Bone Marrow Transplant 2013, 48(5):708-714.

4. Mielcarek M, Martin PJ, Torok-Storb B: Suppression of alloantigen-induced T-cell proliferation by CD14+ cells derived from granulocyte colony-stimulating factor-mobilized peripheral blood mononuclear cells. Blood 1997, 89(5):1629-1634.

5. Aranha FJ, Vigorito AC, De Sousa CA, Oliveira GB, Zulli R, Lorand-Metze I: The influence of the graft monocytes in the outcome of allogeneic bone marrow transplantation. Haematologica 2002, 87(2):219-220.

6. Collins NH, Gee AP, Durett AG, Kan F, Zhang MJ, Champlin RE, Confer D, Eapen M, Howard A, King R, Laughlin MJ, Plante RJ, Setterholm M, Spellman S, Keever-Taylor C, Wagner JE, Weisdorf DJ: The effect of the composition of unrelated donor bone marrow and peripheral blood progenitor cell grafts on transplantation outcomes. Biol Blood Marrow Transplant 2010, 16(2):253-262.

7. Cox CJ, Habermann TM, Payne BA, Klee GG, Pierre RV: Evaluation of the Coulter Counter model S-Plus IV. Am J Clin Pathol 1985, 84(3):297-306.

8. Glucksberg H, Storb R, Fefer A, Buckner CD, Neiman PE, Clift RA, Lerner KG, Thomas ED: Clinical manifestations of graft-versus-host disease in human recipients of marrow from $\mathrm{HL}-\mathrm{A}$-matched sibling donors. Transplantation 1974, 18(4):295-304.

9. Filipovich AH, Weisdorf D, Pavletic S, Socie G, Wingard JR, Lee SJ, Martin P, Chien J, Przepiorka D, Couriel D, Cowen EW, Dinndorf P, Farrell A, Hartzman R, Henslee-Downey J, Jacobsohn D, McDonald G, Mittleman B, Rizzo JD, Robinson M, Schubert M, Schultz K, Shulman H, Turner M, Vogelsang G, Flowers ME: National Institutes of Health consensus development project on criteria for clinical trials in chronic graft-versus-host disease: I. Biol Blood Marrow Transplant 2005, 11(12):945-956. 
10. Kaplan E, Meier P: Nonparametric estimation from incomplete observations. J Am Stat Assoc 1958, 53:457-481.

11. Porrata LF, Gertz MA, Geyer SM, Litzow MR, Gastineau DA, Moore SB, Pineda AA, Bundy KL, Padley DJ, Persky D, Lacy MQ, Dispenzieri A, Snow DS, Markovic SN: The dose of infused lymphocytes in the autograft directly correlates with clinical outcome after autologous peripheral blood hematopoietic stem cell transplantation in multiple myeloma. Leukemia 2004, 18(6):1085-1092.

12. Porrata LF, Litzow MR, Inwards DJ, Gastineau DA, Moore SB, Pineda AA, Bundy KL, Padley DJ, Persky D, Ansell SM, Micallef IN, Markovic SN: Infused peripheral blood autograft absolute lymphocyte count correlates with day 15 absolute lymphocyte count and clinical outcome after autologous peripheral hematopoietic stem cell transplantation in non-Hodgkin's lymphoma. Bone Marrow Transplant 2004, 33(3):291-298

13. Porrata LF, Gastineau DA, Padley D, Bundy K, Markovic SN: Re-infused autologous graft natural killer cells correlates with absolute lymphocyte count recovery after autologous stem cell transplantation. Leuk Lymphoma 2003, 44(6):997-1000.

14. Porrata LF, Inwards DJ, Ansell SA, Micallef IN, Johnston PB, Hogan WJ, Markovic SN: Day 15 Peripheral Blood Lymphocyte/monocyte Ratio PostAutologous Peripheral Hematopoietic Stem Cell Transplantation and Survival in Diffuse Large B-cell Lymphoma. J Stem Cell Res Ther 2011, 1:103.

15. Bolanos-Meade J, Wu J, Logan BR, Levine JE, Ho VT, Alousi AM, Weisdorf DJ, Luznik L: Lymphocyte Phenotype during Therapy for Acute Graft-versusHost Disease: A Brief Report from BMT-CTN 0302. Biol Blood Marrow Transplant, 19(3):481-485.

16. Nakamura R, Auayporn N, Smith DD, Palmer J, Sun JY, Schriber J, Pullarkat V, Parker P, Rodriguez R, Stein A, Rosenthal J, Wang S, Karanas C, Gaal K, Senitzer D, Forman SJ: Impact of graft cell dose on transplant outcomes following unrelated donor allogeneic peripheral blood stem cell transplantation: higher CD34+ cell doses are associated with decreased relapse rates. Biol Blood Marrow Transplant 2008, 14(4):449-457.

17. Kim DH, Won DI, Lee NY, Sohn SK, Suh JS, Lee KB: Non-CD34+ cells, especially CD8+ cytotoxic T cells and CD56+ natural killer cells, rather than CD34 cells, predict early engraftment and better transplantation outcomes in patients with hematologic malignancies after allogeneic peripheral stem cell transplantation. Biol Blood Marrow Transplant 2006, 12(7):719-728

18. Vela-Ojeda J, Garcia-Ruiz Esparza MA, Reyes-Maldonado E, Jimenez-Zamudio L, Garcia-Latorre E, Moreno-Lafont M, Estrada-Garcia I, Montiel-Cervantes L, Tripp-Villanueva F, Ayala-Sanchez M, Garcia-Leon LD, Borbolla-Escoboza JR, Mayani $\mathrm{H}$ : Clinical relevance of NK, NKT, and dendritic cell dose in patients receiving G-CSF-mobilized peripheral blood allogeneic stem cell transplantation. Ann Hematol 2006, 85(2):113-120.

19. Cao TM, Shizuru JA, Wong RM, Sheehan K, Laport GG, Stockerl-Goldstein KE, Johnston L, Stuart MJ, Grumet FC, Negrin RS, Lowsky R: Engraftment and survival following reduced-intensity allogeneic peripheral blood hematopoietic cell transplantation is affected by CD8+ T-cell dose. Blood 2005, 105(6):2300-2306.

20. Lonial S, Akhtari M, Kaufman J, Torre C, Lechowicz MJ, Flowers C, Sinha R, Khoury HJ, Langston AA, Waller EK: Mobilization of hematopoietic progenitors from normal donors using the combination of granulocytemacrophage colony-stimulating factor and granulocyte colony-stimulating factor results in fewer plasmacytoid dendritic cells in the graft and enhanced donor T cell engraftment with Th1 polarization: results from a randomized clinical trial. Biol Blood Marrow Transplant 2013, 19(3):460-467.

21. Holtan SG, Pasquini M, Weisdorf DJ: Acute graft-versus-host disease: a bench-to-bedside update. Blood 2014, 124(3):363-373

22. Maciejewski J, Selleri C, Anderson S, Young NS: Fas antigen expression on CD34+ human marrow cells is induced by interferon gamma and tumor necrosis factor alpha and potentiates cytokine-mediated hematopoietic suppression in vitro. Blood 1995, 85(11):3183-3190.

23. Dybedal I, Bryder D, Fossum A, Rusten LS, Jacobsen SE: Tumor necrosis factor (TNF)-mediated activation of the p55 TNF receptor negatively regulates maintenance of cycling reconstituting human hematopoietic stem cells. Blood 2001, 98(6):1782-1791.

24. Dubey S, Shukla P, Nityanand S: Expression of interferon-gamma and tumor necrosis factor-alpha in bone marrow T cells and their levels in bone marrow plasma in patients with aplastic anemia. Ann Hematol 2005, 84(9):572-577.
25. Yang L, Dybedal I, Bryder D, Nilsson L, Sitnicka E, Sasaki Y, Jacobsen SE: IFN-gamma negatively modulates self-renewal of repopulating human hemopoietic stem cells. J Immunol 2005, 174(2):752-757.

26. Pronk CJ, Veiby OP, Bryder D, Jacobsen SE: Tumor necrosis factor restricts hematopoietic stem cell activity in mice: involvement of two distinct receptors. J Exp Med 2011, 208(8):1563-1570.

27. Cavet J, Middleton PG, Segall M, Noreen H, Davies SM, Dickinson AM: Recipient tumor necrosis factor-alpha and interleukin-10 gene polymorphisms associate with early mortality and acute graft-versushost disease severity in HLA-matched sibling bone marrow transplants. Blood 1999, 94(11):3941-3946.

28. Mullighan C, Heatley S, Doherty K, Szabo F, Grigg A, Hughes T, Schwarer A Szer J, Tait B, To B, Bardy P: Non-HLA immunogenetic polymorphisms and the risk of complications after allogeneic hemopoietic stem-cell transplantation. Transplantation 2004, 77(4):587-596.

29. Mayor NP, Shaw BE, Hughes DA, Maldonado-Torres H, Madrigal JA, Keshav S, Marsh SG: Single nucleotide polymorphisms in the NOD2/CARD15 gene are associated with an increased risk of relapse and death for patients with acute leukemia after hematopoietic stem-cell transplantation with unrelated donors. J Clin Oncol 2007, 25(27):4262-4269.

30. Newell LF, Gooley T, Hansen JA, Stirewalt DL, Petersdorf EW, Deeg HJ: Tumor necrosis factor polymorphism affects transplantation outcome in patients with myelodysplastic syndrome but not in those with chronic myelogenous leukemia, independent of the presence of HLA-DR15. Biol Blood Marrow Transplant 2010, 16(12):1700-1706.

31. Petersdorf EW, Malkki M, Gooley TA, Spellman SR, Haagenson MD, Horowitz MM, Wang T: MHC-resident variation affects risks after unrelated donor hematopoietic cell transplantation. Sci Transl Med 2012, 4(144):144ra101.

32. Melenhorst JJ, Tian X, Xu D, Sandler NG, Scheinberg P, Biancotto A, Scheinberg P, McCoy JP Jr, Hensel NF, Mclver Z, Douek DC, Barrett AJ: Cytopenia and leukocyte recovery shape cytokine fluctuations after myeloablative allogeneic hematopoietic stem cell transplantation. Haematologica 2012, 97(6):867-873.

33. Savani BN, Mielke S, Rezvani K, Montero A, Yong AS, Wish L, Superata J, Kurlander R, Singh A, Childs R, Barrett AJ: Absolute lymphocyte count on day 30 is a surrogate for robust hematopoietic recovery and strongly predicts outcome after T cell-depleted allogeneic stem cell transplantation. Biol Blood Marrow Transplant 2007, 13(10):1216-1223.

34. Burke MJ, Vogel RI, Janardan SK, Brunstein C, Smith AR, Miller JS, Weisdorf D, Wagner JE, Verneris MR: Early lymphocyte recovery and outcomes after umbilical cord blood transplantation (UCBT) for hematologic malignancies. Biol Blood Marrow Transplant 2011, 17(6):831-840.

35. Chang YJ, Zhao XY, Xu LP, Liu DH, Liu KY, Chen YH, Wang Y, Zhang XH, Zhao XS, Han W, Chen H, Wang FR, Lv M, Huang XJ: Early lymphocyte recovery predicts superior overall survival after unmanipulated haploidentical blood and marrow transplant for myelodysplastic syndrome and acute myeloid leukemia evolving from myelodysplastic syndrome. Leuk Lymphoma 2013, 54(12):2671-2677.

36. Delia M, Pastore D, Mestice A, Carluccio P, Perrone T, Gaudio F, Ricco A, Sgherza N, Albano F, Specchia G: Outcome of allogeneic peripheral blood stem cell transplantation by donor graft CD3+/Tregs ratio: a singlecenter experience. Biol Blood Marrow Transplant 2013, 19(3):495-499.

37. Khera N, Zeliadt SB, Lee SJ: Economics of hematopoietic cell transplantation. Blood, 120(8):1545-1551.

38. Dignan FL, Potter MN, Ethell ME, Taylor M, Lewis L, Brennan J, McNamara L, Evans SO, Riley U, Davies FE, Dearden CE, Morgan GJ, Shaw BE: High readmission rates are associated with a significant economic burden and poor outcome in patients with grade III/IV acute GvHD. Clin Transp/ 2013, 27(1):E56-63.

doi:10.1186/2052-1839-14-14

Cite this article as: Thoma et al:: Impact of clinical factors and allograft leukocyte content on post-transplant lymphopenia, monocytopenia, and survival in patients undergoing allogeneic peripheral blood haematopoietic cell transplant. BMC Hematology 2014 14:14. 